\title{
Endoscopic Port Surgery for Paraventricular Brain Metastases Using an Inexpensive Device
}

\author{
Joel Caballero-García1*, Iosmill Morales-Pérez¹, Adolfo Michel Giol-Álvarez², Misael López Sánchez¹, Bismark \\ Rafael Barcia Sánchez ${ }^{1}$ and Carlos Aparicio-García ${ }^{1}$
}

${ }^{1}$ Department of Neurosurgery, National Institute of Oncology and Radiobiology, Cuba

${ }^{2}$ Department of Neurosurgery, Juan Manuel Marquez paediatric hospital, Cuba

Submission: May 21,2018; Published: August 09, 2018

*Corresponding author: Joel Caballero García, Department of Neurosurgery, National Institute of Oncology and Radiobiology, Apto C-12. Vedado. La Habana. Cuba; Tell: 053226881; Email: joelcg@infomed.sld.cu

\section{Abstract}

Objective: During last years a number of tubular retractor systems were described for endoscopically removal of ventricular and periventricular brain tumors. However, these methods are too expensive for underdevelopment countries. In a previously report an inexpensive and simple cylindrical channel retractor was described. We describe the results of this alternative method with some technical variations in a cohort of patients with deep brain metastases and discuss the technical aspects.

Methods: Detailed description of the Endoscopic Port Surgery using an alternative method with illustrative cases.

Results: A total of 6 patients underwent surgical resection of an intraaxial periventricular brain metastases. There were 4 women and 2 men with a mean age of 64,2 years (range, 58-72 years). Clinical presentation was: headache $(n=2)$, seizures $(n=2)$ and hemiparesis $(n=2)$. Lesion location was as follows: frontoparietal $(n=4)$, frontal $(n=1)$ and parietal $(n=1)$. Primary site was as follows: breast $(n=3)$, lung $(n=2)$ and thyroid $(\mathrm{n}=1)$. The average six was 2,9 cm (range, 2,5-3,5 cm). There was gross total resection in all patients. Two patients suffer transient hemiparesis withought other complications. Surgical time average was 135,7 minutes (range, 90-190 minutes). The mean blood loss was $116 \mathrm{ml}$ (range, 50$240 \mathrm{ml}$ ). The mean hospital stay was 6,2 days (range, 5-9 days). The mean following was 6,8 months (range, 4-12 months).

Conclusion: In suitably selected patients with brain metastases, Endoscopic Port Surgery offers a viable option to achieve the goals of tumor surgery with low morbidity and fast recovery. The modified 20-ml syringe can be used as a transparent tubular retractor and it is simple, lightweight, inexpensive and effective. In combination with stereotaxic system and endoscopy can be a good alternative in centers of underdevelopment countries and limited resources.

Keywords: Cylindrical retractor; Endoscopy; Periventricular tumors; Brain metastases; Tumor; Finger glove; Stereotactic; Bone flap; Fashion; Brain spatulas; Manipulation; Stereotactic cannula; Homogeneous; overlying brain; Vascular damage; Complications; Dynamic; Magnification; Skull bone; Bipolar; Meticulous

\section{Introduction}

Intraventricular and periventricular tumors have conventionally been resected through transcortical routes, habitually requiring the use of brain retractors which consist in various types of spatulas to keep the surgical corridor and ensured the microsurgical resection. Nevertheless, this technique does not apply equally distributed pressure and complications as vascular damage, brain edema, seizures and focal neurological deficits are not uncommon [1-4].

To solve this problem a number of tubular retraction systems have been developed with equally distributed pressure which are combined with an endoscopic visualization method to ensure better surgical field illumination and angular vision [5-14]. However, these methods are too expensive for underdevelopment countries. In a previously report Sinhg \& Agrawal [15] described an inexpensive and simple cylindrical channel retractor. We describe the results of this alternative method with some technical variations in six patients with deep brain metastases and discuss the technical aspects.

\section{Methods}

The procedure included general anesthesia, lineal incision and $3 \mathrm{~cm}$ diameter craniotomy based on frame stereotactic guide (Estereoflex system $\left.{ }^{\circledR}\right)$ followed by cruciform dural opening (Figure $1 \mathrm{~A} \& \mathrm{~B}$ ). Transcortical approach was performed by means transgyral way ( $2 \mathrm{~cm}$ corticectomy) according to the stereotactic planned route. Using a finger glove mounted on stereotactic cannula as balloon device, the cannula tip was 


\section{Open Access Journal of Neurology \& Neurosurgery}

advanced to the pre-calculating external lesion point. Them, a dilatation of corticectomy and white subcortical fibers was performed with inflation of balloon using normal saline until it was converted into round opening. The channel retractor was advanced gradually by means repetitive insufflation and partial disinflation of the balloon which put the brain away (Figure $1 \mathrm{~B}$ $\&$ C).
The channel retractor was made of an adapted 20 -ml syringe which length was estimating measuring the distance between the outer table and the external surface of the tumor in coronal RMI or CT reconstruction, so the retractor was rested on skull bone. The working channel have a $2 \mathrm{~cm}$ diameter. Scope, suction cannula and take-apart bipolar device have 4,3 and $5 \mathrm{~mm}$ respectively, so we had $8 \mathrm{~mm}$ of free space for working (Figure $1 \mathrm{D} \& \mathrm{E})$.

\section{Figure 1:}

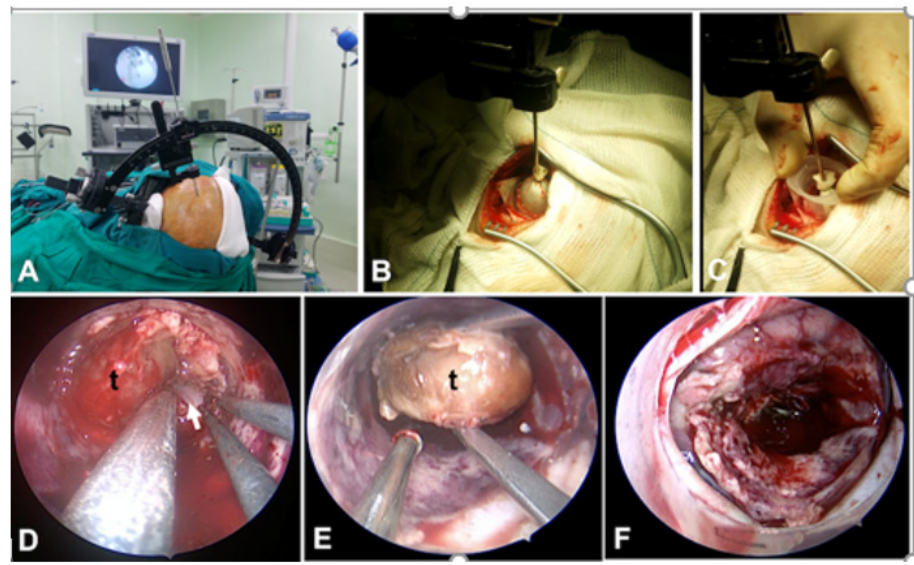

A: Intraoperative photograph showing the Estereoflex stereotactic system $\square$ and the position of video monitor.

$\mathrm{B}$ : Intraoperative photograph exhibiting the finger glove dilatation after a craniotomy of approximately $3 \mathrm{~cm}$ in diameter and a corticectomy of $2 \mathrm{~cm}$.

C: Gradually advancement of cylindrical retractor means repetitive insufflation and partial disinflation of the balloon.

D-F: Intra-operative images of the system and its use.

D: During bimanual microsurgical dissection of the tumor ( $t$ ) next to the ventricular wall (white arrow).

$\mathrm{E}$ : The metastases less than $3 \mathrm{~cm}$ can be resected in "block" manner. The transparent sheath also provides transparent view of surrounding brain.

F: Final view of surgical bed showing preservation of cortical veins and a relaxing brain after minimal retraction.

All lesions were resected under full endoscopic visualization using a $0^{\circ}$ and $30^{\circ}, 4 \mathrm{~mm}, 18 \mathrm{~cm}$ rigid scope (Karl stortz, Germany) and stereotactic guide. The second surgeon hold the scope at 12 o' clock position while the first surgeon performed a standard microsurgical resection with the suction cannula and bipolar or dissection instruments around the seventh and fifth hours respectively. We don't use any scope holder because we prefer a dynamic magnification similar to endonasal endoscopic approach. All lesions were resected in a "in block" fashion due their small size (Figure 1 E \& F \& Figure 2 A \& E).

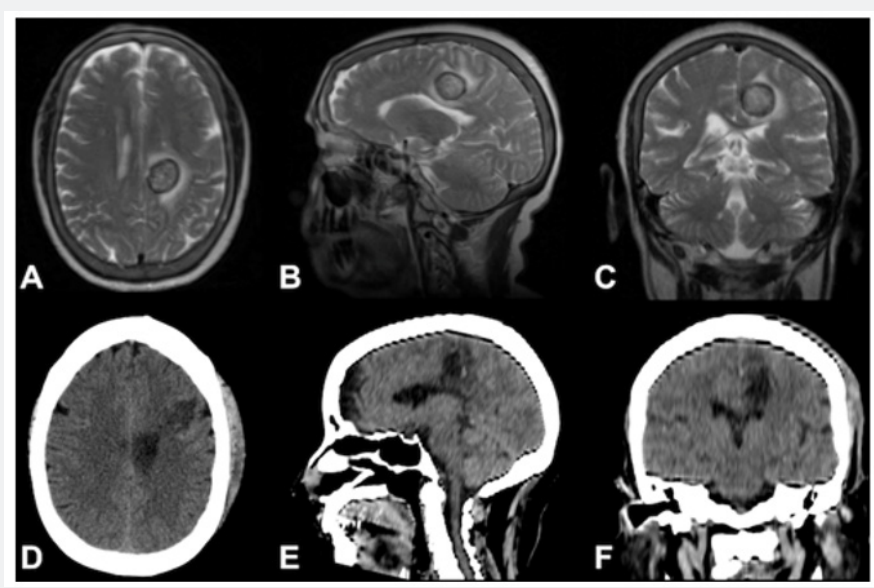

Figure 2: Example of pre- and post-operative images.

A-C: axial, sagittal and coronal T2WI RMI of a solid thyroid brain metastasis bordering the left lateral ventricle.

D-E: 24 hours postoperative axial CT-scan and multiplanar reconstructions showing a complete removal of the lesion with minimal postsurgical edema or bleeding. 
Finally, a meticulous hemostasis of surgical field was performed, then the cavity was irrigated with warm saline and the retractor was carefully retired identifying and cauterizing any bleeding of the surgical corridor (Figure $1 \mathrm{~F}$ ). The cortical entry site was lined with Surgicel, and the dura was then closed in watertight fashion. The bone flap was replaced, and the wound was closed in standard fashion. Patients were extubated in the operation room and stay in the Intensive Care Unit overnight. A 24 hours CT scan was performed to detected any complications (Figure 2 D \& E). Sutures were removed at post-operative day 7.

\section{Results}

A total of 6 patients underwent surgical resection of an intraaxial periventricular brain metastases. There were 4 women and 2 men with a mean age of 64,2 years (range, 5872 years). Clinical presentation was headache $(n=2)$, seizures $(n=2)$ and hemiparesis $(n=2)$. Lesion location was as follows: frontoparietal $(n=4)$, frontal $(n=1)$ and parietal $(n=1)$. Primary site was as follows: breast $(n=3)$, lung $(n=2)$ and thyroid $(n=1)$. The average sixe was $2,9 \mathrm{~cm}$ (range, $2,5-3,5 \mathrm{~cm}$ ). There was gross total resection in all patients. Two patients suffer transient hemiparesis without other complications (Table 1).

Table 1: The demographic, clinical, pathological, radiological and surgical features of the patients.

\begin{tabular}{|c|c|c|c|c|c|c|c|c|}
\hline No & Age/Sex & Presentation & Location & Primary site & Size $(\mathrm{cm})$ & $\begin{array}{l}\text { Extent of } \\
\text { resection }\end{array}$ & $\begin{array}{c}\text { Follow } \\
\text { (months) }\end{array}$ & Complications \\
\hline 1 & $58 / F$ & Headache & $\begin{array}{c}\text { Left } \\
\text { frontoparietal }\end{array}$ & Breast & 2,6 & $\begin{array}{l}\text { Gross total } \\
\text { resection }\end{array}$ & 6 & None \\
\hline 2 & $72 / F$ & Seizures & $\begin{array}{l}\text { Right } \\
\text { frontoparietal }\end{array}$ & Thyroid & 3,5 & $\begin{array}{l}\text { Gross total } \\
\text { resection }\end{array}$ & 12 & $\begin{array}{c}\text { Transient } \\
\text { hemiparesis }\end{array}$ \\
\hline 3 & $68 / M$ & Seizures & Frontal & Lung & 2,6 & $\begin{array}{l}\text { Gross total } \\
\text { resection }\end{array}$ & 4 & None \\
\hline 4 & $63 / F$ & $\begin{array}{l}\text { Left hemi } \\
\text { paresis }\end{array}$ & $\begin{array}{l}\text { Right } \\
\text { frontoparietal }\end{array}$ & Breast & 2,5 & $\begin{array}{l}\text { Gross total } \\
\text { resection }\end{array}$ & 7 & $\begin{array}{c}\text { Transient } \\
\text { hemiparesis }\end{array}$ \\
\hline 5 & $70 / \mathrm{M}$ & Headache & Parietal & Lung & 3,1 & $\begin{array}{l}\text { Gross total } \\
\text { resection }\end{array}$ & 4 & None \\
\hline 6 & 6 & $\begin{array}{l}\text { Left hemi } \\
\text { paresis }\end{array}$ & $\begin{array}{c}\text { Right } \\
\text { frontoparietal }\end{array}$ & Breast & 3,2 & $\begin{array}{l}\text { Gross total } \\
\text { resection }\end{array}$ & 8 & None \\
\hline
\end{tabular}

Duration of surgery ranged from 90 to 190 minutes, with an average 135,7 minutes. The mean blood loss was $116 \mathrm{ml}$ with a range from 50 to $240 \mathrm{ml}$. The mean hospital stay was 6,2 days with a range from 5 to 9 days. The mean following was 6,8 months with a range between 4 and 12 months.

\section{Discussion}

\section{Advantages and disadvantages of tubular retractors and endoscopic visualization}

Since the microscope uses a funneling cone of light for binocular visualization, removal of deep intraparenchymal lesions can require extensive dissection of the overlying brain by using of conventional brain spatulas. In fact, many complications have been reported with the use of brain spatulas like vascular damage, brain edema, seizures and focal neurological deficits
[1-4]. Removal of intra-axial brain tumors using stereotactic guidance and endoscopic visualization was first described in Shelden, et al. [16] and Jacques et al [17]. Otherwise, the first description of the use of a tubular retractor system stereotactic guided for the treatment of the deep-seated intracranial tumors have been attributed to Kelly et al. [18]. In Otsuki, et al. [14] reported the use of a bullet-shaped dilator for stereotacticguides endoscopic tumor resection. This method has enabled neurosurgeons to endoscopic approach deep-seated intraaxial lesions due the fact that the intraparenchymal space not provides natural medium for light dispersion. Subsequently, many groups have published their experience [5-14]. Numerous potential advantages has been reported was as follow:

a) Minimizes the scalp incision associated with small craniotomy size 


\section{Open Access Journal of Neurology \& Neurosurgery}

b) Decreasing white matter disruption as the tip design minimizes the risk of fascicles injury during cannulation;

c) Allowing homogeneous radial dispersion of the pressure on the surrounding tissue;

d) Guaranteeing stability as the rigidity prevents inadvertent expansion of the initial diameter of the corticectomy and white fiber tract dissection throughout surgery;

e) Shielding the surrounding tissues against iatrogenic injuries caused by instrument entry and reentry;

f) Affording constant visualization of the tissue traversed given the transparent conduit design;

g) Offering a wide angle of view and an excellent magnification.

We don't found major complications with this method. In fact, only two patients with brain metastases next to motor eloquent areas suffer transient hemiparesis, possibly related to post operatory edema. The surgical time and blood loss were minimal. However, this method remained limited in their ability to handle larger and more vascular tumors, as they lacked the versatility of the operating microscope as well as its ability to provide multiple angles of tumoral visualization and instruments manipulation. We observed that hemostasis was obtained in somewhat more difficult fashion, but this fact is compensated with the minimized dural opening and white matter manipulation.

The goals of Endoscopic Port Surgery are related to the goals of conventional microsurgical tumor resection: maximal tumor resection with functional neurologic conservation. Tumors with a significant overlying cuff of normal brain parenchyma ( $>1 \mathrm{~cm}$ ), soft consistency (thus favored piecemeal removal), and low or moderate vascularity are the ideal candidates for Endoscopic Port Surgery like primary brain tumors, metastases and cavernous malformations. Renal cell carcinoma metastases are the only exception due their high vascular component. In case of most brain metastases the firm consistency can help to circumferentially spiral dissection and "in toto" resection, which is ideal in these circumstances. Nevertheless, it is necessary to take account that if a resection "in toto" is a goal, the lesion maximum diameter can't extent more than the diameter of the cylindrical retractor. That's why we believe that small brain metastases are the ideal candidates for Endoscopic Port Surgery. On the other hand, lesions much larger than the port itself can be remove adjusting the port angles to $360^{\circ}$ rotation throughout the resection in order to facilitate dynamic lesion visualization. Otherwise, if the long axis of the tumor is perpendicular to the skull, the port can be advantageous by limiting the amount of white matter dissection required for tumor removal.

\section{Commercials and alternatives systems}

There are three main technologic components of any Endoscopic Port Surgery: a. An image guidance (such as neuronavegation, ultrasound or frame stereotactic system)

b. A cylindrical brain retractor (commercials or alternatives)

\section{c. A magnification method (usually the endoscopy)}

Kassam, et al. [19] reported the use of cylindrical retractor relatively similarly to the manner of Dr. Kelly's pioneering work but with a smaller port size $(11.5 \mathrm{~mm})$, completely endoscopic visualization and the use of frameless image-guidance. Some alternatives systems have been described. Kutlay, et al. [20] described a commercially available transparent plastic pediatric anoscope with an inner diameter of $18 \mathrm{~mm}$ and a length of 54mm (Sapimed, S.p.A. Alessandria, Italy). Singh \& Agrawal [15] reported the use of simple method of using a cylindrical channel retractor custom made out of 20cc plastic syringe and a finger glove mounted on brain canula as a balloon device. Corticectomy was performed with the help of ultrasound guidance. It is transparent therefore early detection of haematoma to the surrounding brain is possible. We were using this method with some technical variations. First, our image guidance was a frame stereotactic system, with the balloon device attached to the stereotactic cannula. Second, we advanced the canula with the deinflated balloon attached until the tip was arrived to the external tumor surface and them the canula was gradually dilated and deinflated while the cylindrical channel retractor was advanced. With this simple, lightweight, transparent, freely movable and inexpensive method, effective resection of lesions could be achieved, and the preoperative goals of surgery were seen in all our patients.

\section{Conclusion}

In suitably selected patients with brain metastases, Endoscopic Port Surgery offers a viable option to achieve the goals of tumor surgery with low morbidity and fast recovery. The modified $20-\mathrm{ml}$ syringe can be used as a transparent tubular retractor and it is simple, lightweight, inexpensive and effective. In combination with stereotaxic system and endoscopy can be a good alternative in centers of underdevelopment countries and limited resources.

\section{References}

1. Rosenorn J, Diemer NH (1982) Reduction of cerebral blood ow during brain retraction pressure in the rat. J Neurosurg 56(6): 826-829.

2. Yokoh A, Sugita K, Kobayashi S (1983) Intermittent versus continuous brain retraction. An experimental study. J Neurosurg 58(6): 918- 923.

3. Rosenorn J, Diemer N (1985) The risk of cerebral damage during graded brain retraction pressure in the rat. J Neurosurg 63(4): 608611.

4. Zhong J, Dujovny M, Perlin AR, Perez-Arjona E, Park HK, et al. (2003) Brain retraction injury. Neurol Res 25(8): 831-838.

5. Harris AE, Hadjipanayis CG, Lunsford LD, Lunsford AK, Kassam AB (2005) Microsurgical removal of intraventricular lesions using endoscopic visualization and stereotactic guidance. Neurosurgery 56(1): 125-132 


\section{Open Access Journal of Neurology \& Neurosurgery}

6. Herrera SR, Shin JH, Chan M, Kouloumberis P, Goellner E, et al. (2010) Use of transparent plastic tubular retractor in surgery for deep brain lesions: A case series. Surg Technol Int 19: 47-50.

7. Jho HD, Al eri A (2002) Endoscopic removal of third ventricular tumors: A technical note. Minim Invasive Neurosurg 45(2):114-119.

8. Jo KI, Chung SB, Jo KW, Kong DS, Seol HJ, et al. (2011) Microsurgical resection of deep-seated lesions using transparent tubular retractor: Pediatric case series. Childs Nerv Syst 27(11): 1989- 1994

9. Jo KW, Shin HJ, Nam DH, Lee JI, Park K, et al. (2011) Eficacy of endoportguided endoscopic resection for deep- seated brain lesions. Neurosurg Rev 34(4): 457-463.

10. Almenawer SA, Crevier L, Naresh M, Kassam A, Reddy K (2013) Minimal access to deep intracranial lesions using a serial dilatation technique: case-series and review of brain tubular retractor systems. Neurosurg Rev 36(2): 321-329.

11. Engh JA, Lunsford LD, Amin DV, Ochalski PG, Fernandez- Miranda J, et al. (2010) Stereotactically guided endoscopic port surgery for intraventricular tumor and colloid cyst resection. Neurosurgery 67(3): 198-205.

12. Green eld JP, Cobb WS, Tsouris AJ, Schwartz TH (2008) Stereotactic minimally invasive tubular retractor system for deep brain lesions. Neurosurgery 63(4): 334-340.

13. McLaughlin N, Prevedello DM, Engh J, Kelly DF, Kassam AB (2013) Endoneurosurgical resection of intraventricular and intraparenchyma lesions using the port technique. World Neurosurg 79(2 Suppl): S18. e1-8.

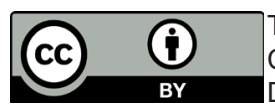

This work is licensed under Creative Commons Attribution 4.0 Licens DOI: 10.19080/OAJNN.2018.08.555731
14. Otsuki T, Jokura H, Yoshimoto T (1990) Stereotactic guiding tube for open-system endoscopy a new approach for the stereotactic endoscopic resection of intra-axial brain tumors. Neurosurgery 27(2): 326-330.

15. Singh L, Agrawal N (2009) Cylindrical channel retractor for intraventricular tumour surgery- a simple and inexpensive device. Acta Neurochir (Wien) 151(11): 1493-1497.

16. Shelden CH, McCann G, Jacques S, Lutes HR, Frazier RE, et al. (1980) Development of a computerized microstereotaxic method for localization and removal of minute CNS lesions under direct 3-D vision. Technical report. J Neurosurg 52: 21-27.

17. Jacques S, Shelden CH, McCann GD, Freshwater DB, Rand R (1980) Computerized three-dimensional stereotaxic removal of small central nervous system lesions in patients. J Neurosurg 53(6): 816-820.

18. Kelly PJ, Goeres SJ, Kall BA (1988) The stereotaxic retractor in computer assisted stereotaxic microsurgery. Technical note. J Neurosurg 69(2): 301-306.

19. Kassam AB, Engh JA, Mintz AH, Prevedello DM (2009) Completely endoscopic resection of intraparenchymal brain tumors. J Neurosurg 110(1): 116-123.

20. Kutlay M, Kural C, Solmaz I, Tehli O, Temiz C, etal.(2016) Fully Endoscopic Resection of Intra-axial Brain Lesions Using Neuronavigated Pediatric Anoscope. Turk Neurosurg 26(4): 1-9.

\section{Your next submission with Juniper Publishers} will reach you the below assets

- Quality Editorial service

- Swift Peer Review

- Reprints availability

- E-prints Service

- Manuscript Podcast for convenient understanding

- Global attainment for your research

- Manuscript accessibility in different formats

( Pdf, E-pub, Full Text, Audio)

- Unceasing customer service

Track the below URL for one-step submission https://juniperpublishers.com/online-submission.php 